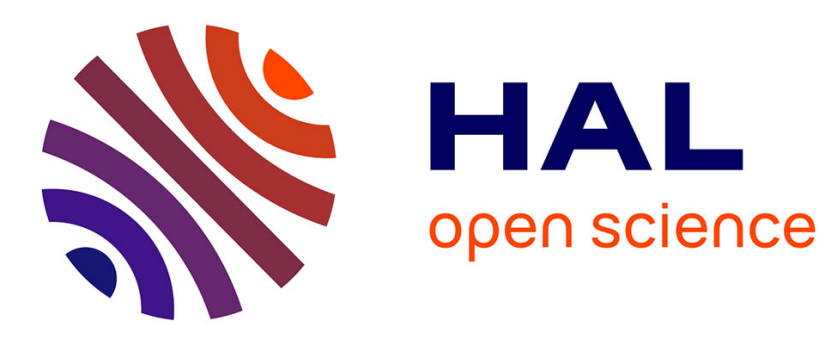

\title{
Stator current demodulation for induction machine rotor faults diagnosis
}

El Houssin El Bouchikhi, Vincent V. Choqueuse, Mohamed Benbouzid, Jose

A. Antonino-Daviu

\section{- To cite this version:}

El Houssin El Bouchikhi, Vincent V. Choqueuse, Mohamed Benbouzid, Jose A. Antonino-Daviu. Stator current demodulation for induction machine rotor faults diagnosis. International Conference on Green Energy 2014, Mar 2014, Sfax, Tunisia. pp.176 - 181, 10.1109/ICGE.2014.6835418 . hal01015474

\section{HAL Id: hal-01015474 https://hal.science/hal-01015474}

Submitted on 26 Jun 2014

HAL is a multi-disciplinary open access archive for the deposit and dissemination of scientific research documents, whether they are published or not. The documents may come from teaching and research institutions in France or abroad, or from public or private research centers.
L'archive ouverte pluridisciplinaire HAL, est destinée au dépôt et à la diffusion de documents scientifiques de niveau recherche, publiés ou non, émanant des établissements d'enseignement et de recherche français ou étrangers, des laboratoires publics ou privés. 


\section{Stator current demodulation for induction machine rotor faults diagnosis}

\author{
El Houssin El Bouchikhi \\ ISEN Brest \\ EA 4325 LBMS \\ Brest, France
}

\author{
Vincent Choqueuse \\ University of Brest \\ EA 4325 LBMS \\ Brest, France
}

\author{
Mohamed Benbouzid \\ University of Brest \\ EA 4325 LBMS \\ Brest, France
}

\author{
Jose A. Antonino-Daviu \\ Dept. Electrical Engigneering \\ Universitat Politècnica de València \\ Camino de Vera $\mathrm{s} / \mathrm{n}$ \\ 46022 Valencia, Spain
}

\begin{abstract}
Several studies have demonstrated that induction machine faults introduce phase and/or amplitude modulation of the stator currents. Hence, demodulation of the stator currents is of high interest for induction machines faults detection and diagnosis. The demodulation techniques can be classified into mono-dimensional and multi-dimensional approaches. The monodimensional techniques include the synchronous demodulator, the Hilbert transform, the Teager energy operator and other approaches. The multi-dimensional approaches include the Concordia transform and the Principal Component Analysis. Once the demodulation has been performed, demodulated signals are further processed in order to measure failure severity. In this paper, we present a comprehensive comparison of these demodulation techniques for eccentricity and broken rotor bars faults detection.
\end{abstract}

Keywords-Induction machine; eccentricity faults; broken rotor bars; diagnosis; stator currents; signal demodulation.

\section{INTRODUCTION}

Condition based maintenance of induction machine in industrial applications is based on performance and parameters monitoring. According to the measurement used, most methods for induction machine monitoring could be classified into several categories: vibration monitoring, torque monitoring, temperature monitoring, oil/debris analysis, acoustic emission monitoring, optical fiber monitoring, and current/power monitoring. Current monitoring has several advantages since it is a non-invasive technique that avoids the use of extra sensors. Hence, most of the recent researches on induction machine faults detection have been directed toward electrical monitoring with emphasis on stator current processing [1], [2].

It has been proven that mechanical and electrical faults lead to stator currents modulation. Mechanical faults lead to eccentricity and load oscillation faults. The eccentricity fault is responsible of the amplitude modulation and the load oscillation leads to frequency modulation of the stator currents [3], [4]. The modulation frequency depends on the operating conditions of the machine as well as on the fault severity. Moreover, adjacent broken bars produce an amplitude modulation in the rotor currents which in turn affects the stator quantities [5].

Generally, the current is sinusoidally frequency and/or amplitude modulated depending on the fault studied. Based on

978-1-4799-3602-1/14/.00 (C)2014 IEEE these findings, it seems that the most adapted tools to extract a fault indicator are the demodulation techniques. Hence, current demodulation has been widely investigated for fault detection and condition monitoring. Typical examples include broken rotor bars detection [6]-[8], gearbox fault detection [9] and bearing fault detection, [3], [10], [11].

The demodulation techniques can be classified into monodimensional and multi-dimensional techniques. The monodimensional techniques include the synchronous demodulator [9], [12], the Hilbert transform [6], [8], [13], time-frequency distributions [14], [15] or adaptive tracking of sine wave [16]. In [6], [7], the authors have used Hilbert transform and Park transform for dynamic rotor faults (broken or cracked rotor bars and dynamic rotor eccentricity) detection. Moreover, the Teager-Kaiser energy operator has been investigated for faults detection in induction machine with broken rotor bars, mixed eccentricity, and single-point bearing faults based on stator current in [17].

The multi-dimensional techniques include the Concordia transform and the Principal Component Analysis (PCA). Joint instantaneous amplitude (IA) and instantaneous frequency (IF) estimation based on the Concordia transform have been investigated in [7], [10], [18]. One advantage of this transform relies on its low computational cost, however, its domain of validity is restricted to balanced three-phase systems. In [10], a technique based on the PCA has been presented for joint IA-IF estimation in unbalanced three-phase systems.

In this paper, the demodulation techniques for rotor faults detection in induction machine are investigated and compared. These techniques are compared for the IA and IF computation and fault severity measurement and tracking. The advantages and drawbacks of each technique are highlighted on simulated data. The contribution of this paper is threefold: First, we present a widely used demodulation techniques for induction machines faults detection. Then, we provide a performance comparison based on simulation data. Finally, we present a fault detection criterion allowing to measure the fault severity.

\section{Demodulation techniques}

Most demodulation techniques rely on the estimation of the analytic signal $z[n]$ of the real-valued signal $x[n]$. These approaches can be classified into mono-dimensional and multidimensional techniques. 


\section{A. Mono-dimensional techniques}

The mono-dimensional techniques require 1-D signal in order to compute the IA and IF. Let us denote $x[n]$ a singlephase stator current. If $x[n]=a[n] \cos [\Phi[n]]$ is a real-valued signal, the corresponding analytic signal is given by

$$
z[n]=a[n] e^{j \Phi[n]}
$$

Once the analytic signal is computed, the IA $a[n]>0$ and the IF $f[n]>0$ can simply be estimated as

$$
\begin{aligned}
& \widehat{a}[n]=|z[n]| \\
& \widehat{f}[n]=\frac{1}{2 \pi}(\angle(z[n+1])-\angle(z[n])) \times F_{s}
\end{aligned}
$$

where $F_{s}$ is the sampling rate and where $|$.$| and \angle($.$) are$ the modulus and the argument of complex-valued signal $z[n]$, respectively.

1) Synchronous demodulator: To detect the modulation introduced by induction machine faults, a synchronous demodulation can be used in order to estimate IA and IF.

Let's consider that the instantaneous phase is given by: $\Phi[n]=2 \pi f_{0} n+\varphi[n]$ and assume that the carrier frequency $f_{0}$ is known [19]. The synchronous demodulation includes multiplying the signal $x[n]$ by two conjugate reference signals $\cos \left(2 \pi f_{0} n / F_{s}\right)$ and $\sin \left(2 \pi f_{0} n / F_{s}\right)$. Where $f_{0}$ is the central frequency of the signal $x[n]$. Low-pass filtering of the multiplied signals gives two low-frequency signals that directly reflect IA and IF. A Butterworth low-pass filter with cutoff frequency of $50 \mathrm{~Hz}$ has been used. The SD scheme is illustrated by Fig. 1 .

The discrete time analytic signal can be computed as follows

$$
z^{s}[n]=x_{1}^{s}[n]+j x_{2}^{s}[n]=a[n] e^{j \varphi[n]}
$$

One of the drawbacks of the SD is the filtering stage tuning and a long time before convergence.

The SD has been used for multistage gearbox diagnosis using amplitude demodulation of the current waveform in [9].

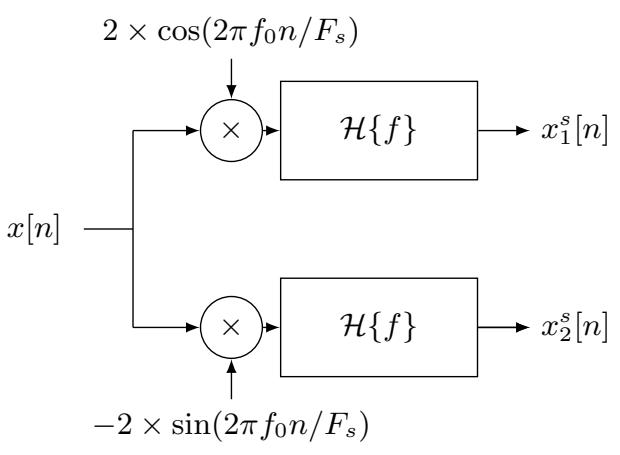

Fig. 1. Synchronous Demodulator. $\mathcal{H}\{f\}$ corresponds to the frequency response of the low-pass filter $h[n]$.

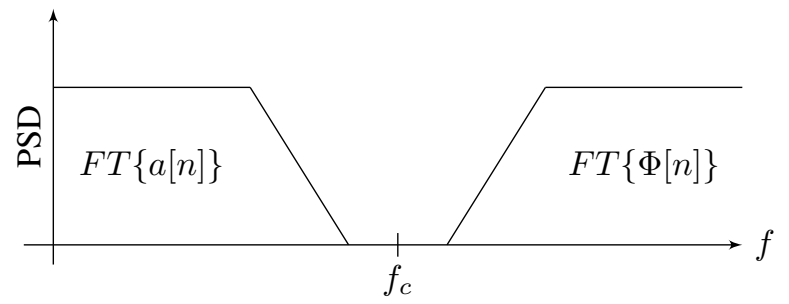

Fig. 2. Illustration of the Bedrosian theorem conditions.

2) Hilbert transform: The Hilbert transform (HT) is a classical technique in signal processing for the estimation of the analytic signal. For a discrete signal $x[n]$, the Hilbert transform is given by [20]

$$
x^{h}[n]=x[n] * h[n],
$$

where, $h[n]$ is an impulse response which is defined as

$$
h[n]=\left\{\begin{array}{lr}
0 & \text { for } \mathrm{n} \text { even } \\
\frac{2}{\pi n} & \text { for } \mathrm{n} \text { odd }
\end{array}\right.
$$

The Bedrosian theorem dealing with Hilbert transform of two real functions product, has shown that the uniqueness of the IF and the IA is satisfied if and only if the spectra of the IA and the sinus of the instantaneous phase are disjoint [21] (see Fig 2). Under Bedrosian conditions, the analytic signal $z^{h}[n]$ associated with $x[n]$ is defined as [22]

$$
z^{h}[n]=x[n]+j x^{h}[n]=a[n] e^{\Phi[n]}
$$

The Hilbert transform can be computed for a real valued $N$ point discrete time signal efficiently using the FFT algorithm [23]. One of the disadvantages of HT is the border effect.

The Hilbert transform has been employed for MCSA to detect eccentricity and bar breakages in transient conditions in [8], [24]. In [25] the Hilbert transform has been used to process the stator current in PMSM to diagnose demagnetization.

3) Teager energy operator: The Teager energy operator (TEO) allows to track the IF and the IA of a modulated signal without computing the analytic signal [26]. The discrete-time TEO is given by [27]

$$
\Psi(x[n])=x^{2}[n]-x[n+1] x[n-1]
$$

It can be noticed that the TEO is local operator which allows to capture the energy fluctuations with good time resolution since it requires only three samples $(x[n-1], x[n]$, and $x[n+$ 1]). In [27], the authors have presented an estimator of the IA and the IF of a signal based on the TEO, which is called the Energy Separation Algorithm (ESA):

$$
\begin{aligned}
& a[n] \approx \sqrt{\frac{\Psi[x[n]]}{1-\left(1-\frac{\Psi[x[n]-x[n-1]]}{2 \Psi[x[n]]}\right)^{2}}} \\
& f[n] \approx \frac{1}{2 \pi} \operatorname{arcos}\left(1-\frac{\Psi[x[n]-x[n-1]]}{2 \Psi[x[n]]}\right)
\end{aligned}
$$


The ESA exhibits interesting property since it is less computationally demanding and had better time resolution than other demodulation techniques. The main drawback of this operator is its sensitivity to noise or to model mismatch. Moreover, it assumes that the estimated IF does not vary too fast or too greatly compared to carrier frequency [27]. The ESA has been used for bearing faults detection based on the vibration signals in [28]. In [17], the Teager-Kaiser energy operator has been investigated for faults detection in induction machine with broken rotor bars, mixed eccentricity, and single-point bearing faults based on stator current.

\section{B. Multi-dimensional techniques}

The multi-dimensional techniques require a $3-D$ stator current. In this case, let us denote $\mathbf{x}[n]=\left[x_{1}[n], x_{2}[n](t), x_{3}[n]\right]^{T}$ the $3 \times 1$ vector containing the stator currents.

1) Concordia transform approach: The Concordia transform (CT) is a multidimensional linear transform which allows to extract a two orthogonal components from the three-phase stator currents. Let's denote $\mathbf{x}^{c}[n]=\left[x_{1}^{c}[n], x_{2}^{c}[n]\right]^{T}$ the two Concordia components. The $\mathrm{CT}$ can be expressed into a matrix form as [18], [29], [30]

$$
\mathbf{x}^{c}[n]=\left[\begin{array}{l}
x_{1}^{c}[n] \\
x_{2}^{c}[n]
\end{array}\right]=\sqrt{\frac{2}{3}}\left[\begin{array}{ccc}
\frac{\sqrt{2}}{\sqrt{3}} & -\frac{1}{\sqrt{6}} & -\frac{1}{\sqrt{6}} \\
0 & \frac{1}{\sqrt{2}} & -\frac{1}{\sqrt{2}}
\end{array}\right] \mathbf{x}[n]
$$

Under the assumption of a balanced system, it can be demonstrated that the analytic signal $z^{c}[n]$ is given by [31]

$$
z^{c}[n]=x_{1}^{c}[n]+j x_{2}^{c}[n]=a[n] e^{j \Phi[n]}
$$

The main drawback of CT is the fact that it is based on the assumption of balanced system. This assumption is rarely verified in three phase systems especially in the case of abnormal operating conditions.

The CT performance has been compared with HT for three phase machine stator current time-frequency monitoring in [18]. In [32], the CT was combined with ESPRIT to improve its performance for detecting rotor fault in induction machine at low slip.

2) Principal component analysis approach: Principal Component Analysis (PCA) is a statistical tool that transforms a number of correlated signals into a small number of uncorrelated components, called the principal components. The principal components of $\mathbf{x}[n]$, denoted $\mathbf{x}^{p}[n]=\left[x_{1}^{p}[n], x_{2}^{p}[n]\right]^{T}$ are given by

$$
\mathbf{x}^{p}[n]=\left[\begin{array}{l}
x_{1}^{p}[n] \\
x_{2}^{p}[n]
\end{array}\right]=\beta \Lambda^{\frac{-1}{2}} \mathbf{S}^{T} \mathbf{x}[n]
$$

where $\beta$ is a scaling term given by

$$
\beta=\sqrt{\frac{\operatorname{Tr}\left[\mathbf{R}_{x}\right]}{3}}
$$

where the operator $\operatorname{Tr}[$.$] is defined to be the sum of the$ elements on the main diagonal. The covariance matrix $\mathbf{R}_{x}$ of $\mathbf{x}[n]$ is defined as

$$
\mathbf{R}_{x}=E\left[\mathbf{x}[n] \mathbf{x}^{T}[n]\right]=\mathbf{U} \Lambda \mathbf{U}^{T}
$$

with $\Lambda$ and $\mathbf{U}=[\mathbf{S} \mathbf{G}]$ are matrices containing the eigenvalues and eigenvectors of $\mathbf{R}_{x}$, respectively.

Under the assumptions that $\Phi[n]$ is uniformly distributed in $[0 ; 2 \pi]$ and that $a[n]$ and $\Phi[n]$ are independent, it can be demonstrated that the analytic signal $z^{p}[n]$ can be estimated up to a phase indetermination as [29]

$$
z^{p}[n]=x_{1}^{p}[n]+j x_{2}^{p}[n]=a[n] e^{j \Phi[n]} e^{-j \theta} .
$$

where $\theta$ is an unknown phase.

As opposed to Concordia transform, the PCA-based demodulation is less restrictive since it holds whatever the balance assumption which is interesting for fault detection in electrical machine.

The PCA has been used for bearing faults detection in induction machine and compared with CT in [29]. In [33], the stator current has been processed to extract alpha-beta using Park/Concordia approach as well as PCA for principal components computation. These components are then used as input for an unsupervised neural network for on-line stator faults diagnostic of induction machine.

\section{Faults detection based on demodulation techniques algo- rithm}

After demodulation, the analytic signal and the corresponding IA and IF must be appropriately analyzed to assess the fault severity. Several papers have proposed to monitor the deviation of the analytic signal from a circle in the complex plane [34], [35]. This approach holds when the stator current is amplitude modulated but is not appropriate when the stator current is frequency modulated since the fault only affects the rotational speed in the complex plane [29]. Hence, in order to measure the fault severity, the variance of the IA, $a[n]$ and the IF, $f[n]$ are used as a fault detection criteria. In fact, it can be inferred from [29] that the proposed criteria are related to the modulation indexes which are proportional to the fault severity.

$$
\begin{aligned}
& \mathcal{C}_{1}=\mathrm{E}\left[(\widehat{a}[n]-\mathrm{E}(\widehat{a}[n]))^{2}\right] \\
& \mathcal{C}_{2}=\mathrm{E}\left[(\widehat{f}[n]-\mathrm{E}(\widehat{f}[n]))^{2}\right]
\end{aligned}
$$

\section{Simulation RESUlTS}

This section reports on the performance of the studied demodulation techniques. The induction machine modelling approach is briefly presented. Then, the demodulation techniques are used for eccentricity and broken rotor bars faults detection in induction machine. 


\section{A. Induction machine modelling under faults briefly}

An induction machine is considered as a highly symmetrical electromagnetic system. Any fault will therefore induce a certain degree of asymmetry [36]. The coupled magnetic circuits (CMC) approach combined with the arbitrary reference frames theory have been chosen for induction machines modelling [37]. In this context, a Matlab ${ }^{\circledR}$-based tool of faulty induction machines has been developed to generate a fault database.

Under some assumptions [38], the representation of an induction machine with a cage rotor is fundamentally the same as one with a phase wound rotor, where it is assumed that the cage rotor can be replaced by a set of mutually coupled loops.

The system of differential equations describing the behaviour of induction machine with 3 stator phases and $q$ rotor bars can be written in vector matrix form as follows (16) [38]

$$
\left\{\begin{array}{l}
\frac{d}{d t} \mathbf{I}=-\mathbf{L}^{-1}\left(\mathbf{R}+\Omega \frac{d}{d \theta_{m}} \mathbf{L}\right) \mathbf{I}+\mathbf{L}^{-1} \mathbf{V} \\
\frac{d}{d t} \Omega=\frac{1}{2 J} \mathbf{I}^{T}\left(\frac{d}{d \theta_{m}} \mathbf{L}\right) \mathbf{I}-\frac{f}{J} \Omega-\frac{1}{J} \Gamma_{C} \\
\frac{d}{d t} \theta_{m}=\Omega
\end{array}\right.
$$

where,

- $J, f$, and $\Gamma_{c}$ represent the rotating masses inertia, the viscous friction coefficient, and load torque, respectively.

$-\frac{d}{d t}[$.$] and \frac{d}{d \theta_{m}}[$.$] are the derivatives with respect to time$ and to the angular position, respectively.

- $\Omega$ and $\theta_{m}$ are the rotor mechanical speed and the rotor angular position, respectively.

- $\mathbf{V}$ is the voltage vector, which is given by

$$
\mathbf{V}=\left[\begin{array}{ll}
\mathbf{V}_{s} & \mathbf{V}_{r}
\end{array}\right]^{T} \Leftrightarrow\left\{\begin{array}{l}
\mathbf{V}_{s}=\left[\begin{array}{llll}
v_{s 1} & v_{s 2} & v_{s 3}
\end{array}\right] \\
\mathbf{V}_{r}=\left[\begin{array}{lllll}
0 & 0 & 0 & \ldots & 0
\end{array}\right]_{1 \times(q+1)}
\end{array}\right.
$$

- I is the current vector, which is defined as

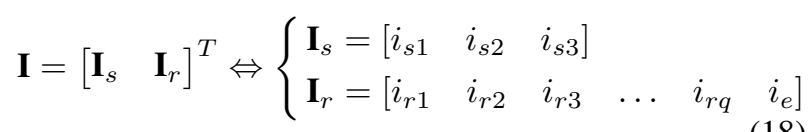

- $\mathbf{R}$ is the global resistance matrix given by

$$
\mathbf{R}=\left[\begin{array}{cc}
\mathbf{R}_{s} & \mathbf{0}_{3 \times(n+1)} \\
\mathbf{0}_{(n+1) \times 3} & \mathbf{R}_{r}
\end{array}\right]
$$

where $\mathbf{R}_{s}$ is the stator resistance matrix. The $(q+1) \times$ $(q+1)$ symmetric matrix $\mathbf{R}_{r}$ corresponds to rotor cage resistances.

- The global matrix inductance can be presented by

$$
\mathbf{L}=\left[\begin{array}{ll}
\mathbf{L}_{s s} & \mathbf{M}_{s r} \\
\mathbf{M}_{r s} & \mathbf{L}_{r r}
\end{array}\right]
$$

The stator inductance matrix $\mathbf{L}_{s s}$ is symmetric with constant elements, $M_{s}$ is the mutual inductance between the stator phases, and $L_{s 1}, L_{s 2}, L_{s 3}$ are the total inductances of the stator coil which represents the sum of the magnetizing inductance for each stator coil $L_{m s}$ and

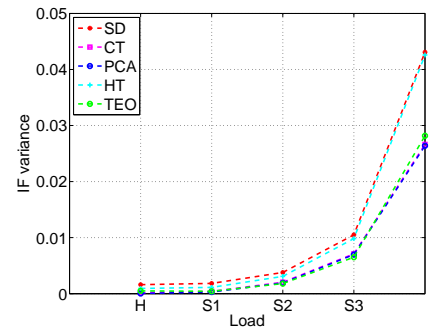

(a) IF variance: $\mathcal{C}_{1}$.

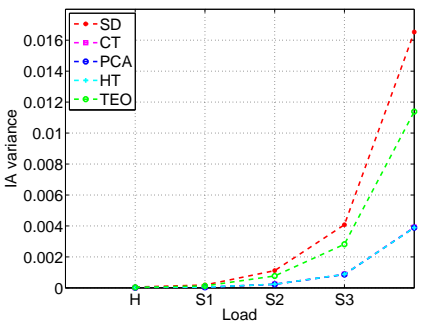

(b) IA variance: $\mathcal{C}_{2}$.
Fig. 4. Fault detection criteria with respect to fault severity; S1: $5 \%$ eccentricity, S2: $10 \%$ eccentricity, S3: $15 \%$ eccentricity, S4: $20 \%$ eccentricity.

the leakage inductance $L_{s f}$. Finally, $\mathbf{L}_{r r}$ corresponds to the inductance matrix of the rotor loops and the mutual inductance $\mathbf{M}_{s r}$ is a $3 \times q$ matrix consisting of mutual inductances between stator coils and rotor loops.

In the following, all the relevant inductances matrices in $\mathbf{L}$ are calculated using the winding function method [39], [40]. In this section, a $4 \mathrm{~kW}$ induction machines operating under nominal load condition have been simulated. Three machines have been considered: a healthy machine, a faulty one affected by a (static, dynamic and mixed) eccentricity, and a faulty machine with broken rotor bars. Simulations have been performed during 10 seconds. The stator currents have been sampled with a $1 \mathrm{kHz}$ sampling rate. The first second corresponding to transient has been removed. In order to obtain an approximation of a mono-component signal, the current is bandpass filtered with upper and lower cut-off frequencies equal to $90 \mathrm{~Hz}$ and $10 \mathrm{~Hz}$, respectively. For the sake of brevity, we chose to only present the mixed eccentricity results and broken rotor bars.

\section{B. Eccentricity fault detection}

The simulation results for the estimation of the IA and IF using the demodulation techniques are given by Fig. 3 .

The main conclusion that may be drawn from these figures is that the demodulation techniques allow to highlight the presence of mixed eccentricity. Moreover, the mixed eccentricity introduces both a sinusoidal frequency and amplitude modulation in the stator current when a fault occurs. In order to demonstrate the interest of using these techniques for fault detection and severity measurement, several simulations have been conducted and the variation of the proposed fault detection criteria with respect to fault severity is given by Fig.4.

Figure 4 shows that the proposed fault detection algorithm allows to measure the fault severity. In fact, the fault detection criteria are greater as the fault severity increases. These simulation results demonstrate the interest of the proposed algorithm for faults detection in induction machine.

\section{Broken rotor bars detection}

Similarly to eccentricity fault, the proposed algorithm has been investigated for broken rotor bars detection. The broken 

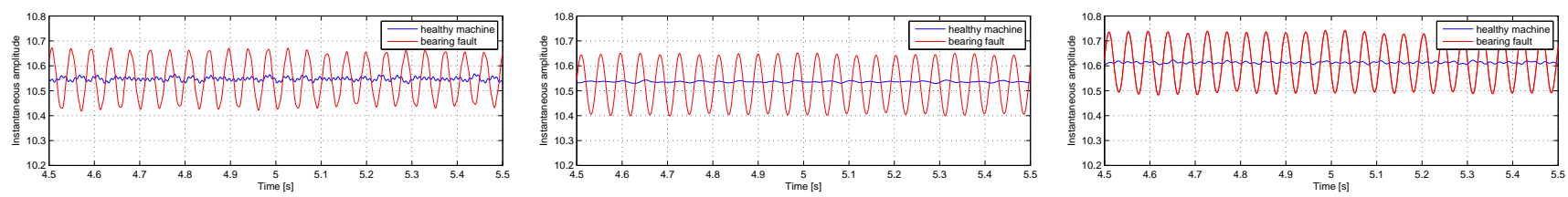

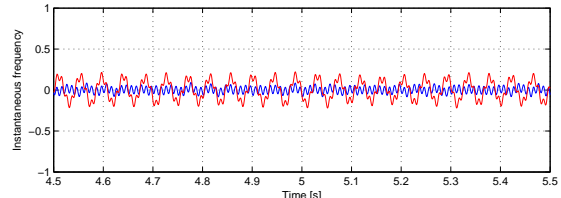

(a) Synchronous demodulator-based demodulation.

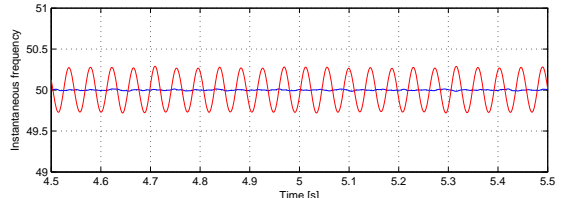

(b) Concordia transform-based demodulation.

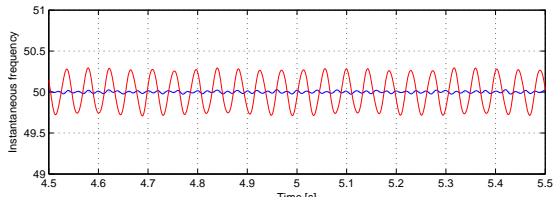

(c) Principal component analysis-based demodulation.
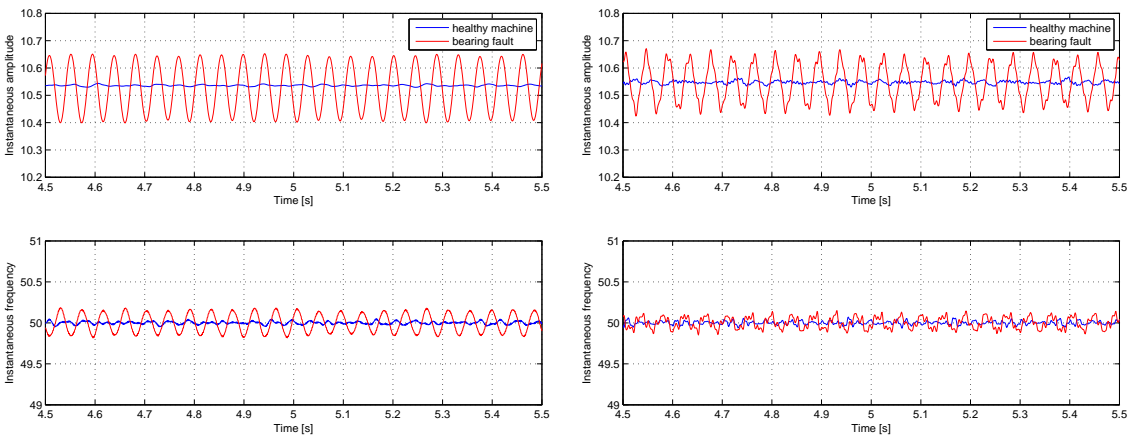

(d) Hilbert transform-based demodulation.

(e) Teager energy operator-based demodulation.

Fig. 3. Stator current demodulation for eccentricity fault detection.

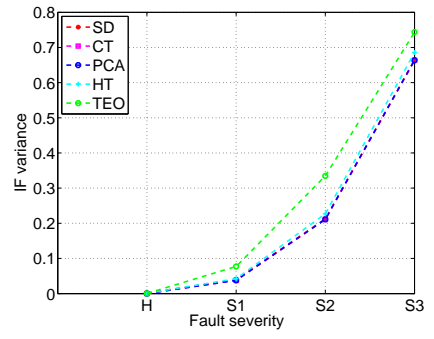

(a) IF variance: $\mathcal{C}_{1}$.

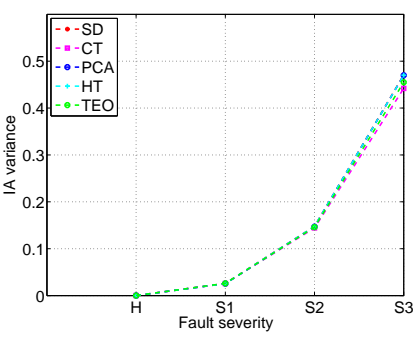

(b) IA variance: $\mathcal{C}_{2}$.
Fig. 5. Fault detection criteria with respect to fault severity for adjacent broken bars; S1: 1 Broken rotor bar, S2: 2 Broken rotor bars, S3: 3 Broken rotor bars.

bars have been performed by considering the correspondent resistance as infinite.

The simulation results are depicted in Fig. 5 for adjacent broken rotor bars.

These results show that the broken rotor bars introduce both amplitude and frequency modulation of the stator currents. The proposed criteria allow to measure the number of broken rotor bars since the fault detection criteria are proportional to faults severity for adjacent broken bars. For non-adjacent rotor bars, the proposed algorithm allows to identify the broken bars fault but does not allow to give an indication about the number of broken bars.

\section{Discussion}

These results suggest that the presented demodulation techniques are equivalent for faults detection in induction machine. However, each technique has its own advantages and drawbacks. For a mono-dimensional signal, a standard approach is based on the HT. However, the HT assumes that the Bedrosian theorem conditions are satisfied. Moreover, this technique suffers from border effects which may increase the criteria values. The TEO is quite attractive since it requires only three samples but it is sensitive to noise and assumes that the IF does not vary too fast. Finally, the SD is easy to implement but it assumes the carrier frequency as known. Moreover, filtering stage tuning is quite difficult and induce a long time before convergence.

For a multi-dimensional signals, the CT and PCA are interesting techniques for IA and IF computation. The main drawback of CT is its domain of validity since it works only for balanced three-phase systems. On the contrary, the PCA is well suited for an unbalanced system. However, the PCA performance depends on the signal covariance matrix estimator and the signal and noise subspaces separation.

\section{CONCLusion}

In this paper, we have investigated the demodulation techniques for rotor faults detection in induction machine. It has been shown that the computation of the variance of IF and IA allows to derive a reliable fault detection criteria. The performance of the proposed techniques has been evaluated for 
the demodulation of simulated signals issued from a coupled magnetic circuits model of a $4 \mathrm{~kW}$ squirrel cage induction machine. Further investigations are required in order to prove the usefulness of the proposed techniques for actual induction machine rotor and stator faults detection.

\section{REFERENCES}

[1] A. Bellini, F. Filippetti, C. Tassoni, and G. A. Capolino, "Advances in diagnostic techniques for induction machines," IEEE Transactions on Industrial Electronics, vol. 55, no. 12, pp. 4109-4126, December 2008.

[2] M. E. H. Benbouzid, "A review of induction motors signature analysis as a medium for faults detection," IEEE Trans. Industrial Electronics, vol. 47, no. 5, pp. 984-993, October 2000.

[3] M. Blodt, J. Regnier, and J. Faucher, "Distinguishing load torque oscillations and eccentricity faults in induction motors using stator current wigner distributions," IEEE Transactions on Industry Applications, vol. 45, no. 6, pp. 1991-2000, 2009.

[4] M. Blodt, J. Faucher, B. Dagues, and M. Chabert, "Mechanical load fault detection in induction motors by stator current time-frequency analysis," IEEE Transactions on Industry Applications, vol. 55, no. 2, pp. 522-533, 2008.

[5] A. Stefani, A. Bellini, and F. Filippetti, "Diagnosis of induction machines rotor faults in time-varying conditions," IEEE Transactions on Industrial Electronics, vol. 56, no. 11, p. 45484556, 2009.

[6] I. Jaksch and P. Fuchs, "Rotor cage faults detection in induction motors by motor current demodulation analysis," in SDEMPED, Cracow, Poland, 2005, pp. 247-252.

[7] _ "Demodulation analysis for exact rotor faults detection under changing parameters," in SDEMPED, Cargse, France, 2009, pp. 1-7.

[8] M. Pineda-Sanchez and M. Riera-Guasp, "Instantaneous frequency of the left sideband harmonic during the start-up transient: A new method for diagnosis of broken bars," IEEE Transactions on Industrial Electronics, vol. 56, no. 11, pp. 4557-4570, 2009

[9] A. Mohanty and C. Kar, "Fault detection in a multistage gearbox by demodulation of motor current waveform," IEEE Transactions on Industrial Electronics, vol. 53, no. 4, pp. 1285-1297, 2006.

[10] V. Choqueuse, M. Benbouzid, Y. Amirat, and S. Turri, "Diagnosis of three-phase electrical machines using multidimensional demodulation techniques," IEEE Transactions on Industrial Electronics, vol. 59, no. 4 pp. $2014-2023$, april 2012.

[11] Y. Amirat, V. Choqueuse, and M. Benbouzid, "Eemd-based wind turbine bearing failure detection using the generator stator current homopolar component," Mechanical Systems and Signal Processing, vol. 41, no. 1, pp. 667-678, 2013.

[12] M. Akke, "Frequency estimation by demodulation of two complex signals," IEEE Transactions on Energy Conversion, vol. 12, no. 1, pp. 157-163, 1997.

[13] R. Puche-Panadero, M. Pineda-Sanchez, M. Riera-Guasp, J. RogerFolch, E. Hurtado-Perez, and J. Perez-Cruz, "Improved Resolution of the MCSA Method Via Hilbert Transform, Enabling the Diagnosis of Rotor Asymmetries at Very Low Slip," IEEE Transactions on Energy Conversion, vol. 24, no. 1, pp. 52-59, Mar. 2009.

[14] M. Blodt, M. Chabert, J. Regnier, and J. Faucher, "Mechanical load fault detection in induction motors by stator current time-frequency analysis," IEEE Transactions on Industry Applications, vol. 42, no. 6, pp. 14541463, 2006

[15] M. Blodt, D. Bonacci, J. Regnier, M. Chabert, and J. Faucher, "Online monitoring of mechanical faults in variable-speed induction motor drives using the wigner distribution," IEEE Transactions on Industrial Electronics, vol. 55, no. 2, pp. 522-533, 2008

[16] P. Dash and S. Hasan, "A fast recursive algorithm for the estimation of frequency, amplitude, and phase of noisy sinusoid," IEEE Transactions on Industrial Electronics, vol. 58, no. 10, pp. 4847 -4856, oct. 2011.

[17] M. Pineda-Sanchez, R. Puche-Panadero, M. Riera-Guasp, J. PerezCruz, J. Roger-Folch, J. Pons-Llinares, V. Climente-Alarcon, and J. A. Antonino-Daviu, "Application of the teager-kaiser energy operator to the fault diagnosis of induction motors," IEEE Trans. on Energy Conversion., vol. pp, no. 99, pp. 1-9, 16 Sept. 2013.

[18] B. Trajin, M. Chabert, J. Regnier, and J. Faucher, "Hilbert versus Concordia transform for three-phase machine stator current time-frequency monitoring," Mechanical Systems and Signal Processing, vol. 23, no. 8, pp. 2648-2657, Nov. 2009 .
[19] P. Stoica and R. Moses, Introduction to Spectral Analysis. Prentice Hall, 1997.

[20] S. L. Hahn, Hilbert Transforms in Signal Processing. Norwell, MA: Artech House, 1996.

[21] B. Picinbono, "On instantaneous amplitude and phase of signals," IEEE Transactions on Signal Processing, vol. 45, no. 3, pp. 552-560, 1997.

[22] B. Boashash, Time-Frequency signal analysis, in advances in Spectrum Estimation, S. Haykin, Ed. Engewood Cliffs, NJ: Prentice-Hall, 1991.

[23] L. Marple Jr, "Computing the discrete-time analytic signal via fft," Signal Processing, IEEE Transactions on, vol. 47, no. 9, pp. 2600-2603, 1999.

[24] J. Pons-Llinares, J. Roger-Folch, and M. Pineda-Sanchez, "Diagnosis of eccentricity based on the hilbert transform of the startup transient current," in Procedings of SDEMPED'09, Cargese, France, Aug./Sept. 2009, pp. 1-6.

[25] A. Espinosa, J. Rosero, J. Cusido, L. Romeral, and J. Ortega, "Fault detection by means of hilbert-huang transform of the stator current in a pmsm with demagnetization," IEEE Transactions on Energy Conversion, vol. 25 , no. 2, pp. 312-318, 2010 .

[26] P. Maragos, J. Kaiser, and T. Quartieri, "On amplitude and frequency demodulation using energy operators," IEEE Transactions on Signal Processing, vol. 41, no. 4, 1993.

[27] P. Maragos, J. Kaiser, and T. Quatieri, "Energy separation in signal modulations with application to speech analysis," IEEE Transactions on Signal Processing, vol. 10, no. 41, pp. 3024-3051, 1993.

[28] H. Li, L. Fu, and Y. Zhang, "Bearing fault diagnosis based on teager energy operator demodulation technique," in International Conference on Measuring Technology and Mechatronics Automation, Zhangjiajie, China, 2009, pp. 594-597.

[29] V. Choqueuse, M. E. H. Benbouzid, Y. Amirat, and S. Turri, "Diagnosis of three-phase electrical machines using multidimensional demodulation techniques," IEEE Transactions on Industrial Electronics, vol. 59, no. 4, pp. 2014-2023, April 2011.

[30] I. Onel and M. Benbouzid, "Induction motor bearing failure detection and diagnosis: Park and concordia transform approaches comparative study," IEEE/ASME Transactions on Mechatronics, vol. 13, no. 2, pp. 257-262, 2008

[31] J. M. Aller, A. Bueno, and T. Pagá, "Power system analysis using spacevector transformation," Power Systems, IEEE Transactions on, vol. 17 no. 4, pp. 957-965, 2002.

[32] B. Xu, L. Sun, L. Xu, and G. Xu, "Improvement of the hilbert method via esprit for detecting rotor fault in induction motors at low slip," IEEE Transactions on Energy Conversion, vol. 28, no. 1, pp. 225-233, March 2013.

[33] J. Martins, V. F. Pires, and A. Pires, "Unsupervised neural-networksbased algorithm for on-line diagnosis of three-phase induction motor stator fault," IEEE Transactions on Industrial Electronics, vol. 54, no. 1, pp. 259-264, 2007.

[34] S. Das, P. Purkait, and S. Chakravorti, "Space-vector characterization of induction motor operating conditions," in Fifteen National Power System Conference, Bombay, India, 2008, pp. 512-517.

[35] D. Diallo, M. Benbouzid, D. Hamad, and X. Pierre, "Fault detection and diagnosis in an induction machine drive: A pattern recognition approach based on concordia stator mean current vector," IEEE Transactions on Energy Conversion, vol. 20, no. 3, pp. 512-519, 2005.

[36] H. Toliyat, M. Arefeen, and A. Parlos, "A method for dynamic simulation of air-gap eccentricity in induction machines," IEEE Trans. Industry Applications, vol. 32, no. 4, pp. 910-918, July/August 1996.

[37] H. Toliyat and T. Lipo, "Transient analysis of cage induction machines under stator, rotor bar and end ring faults," IEEE Trans. Energy Conversion, vol. 10, no. 2, pp. 241-247, June 1995.

[38] G. Houdouin, "Contribution la modlisation de la machine asynchrone en prsence de dfauts rotoriques," Ph.D. dissertation, Universit du Havre, Le Havre, 2004.

[39] E. H. El Bouchikhi, V. Choqueuse, and M. E. H. Benbouzid, "Current frequency spectral subtraction and its contribution to induction machines' bearings condition monitoring," IEEE Trans. on Energy Conversion, vol. 28, no. 1, pp. 135-144, March 2013.

[40] G. Joksimovic, M. Durovic, J. Penman, and N. Arthur, "Dynamic simulation of dynamic eccentricity in induction machines-winding function approach," IEEE Trans. Energy Conversion, vol. 15, no. 2, pp. 143-148, June 2000. 